\title{
TUSSOCK GRASSLANDS IN THE SOUTH ISLAND OF NEW ZEALAND
}

\author{
By J. M. HERCUS, Instructor in Agriculture, \\ Department of Agriculture, Alexandra.
}

More than 13 million acres, nearly one-third of the occupied, land of New Zealand, are described, as tussock grassland, and much the greater part of these are in the South Island. Before occupation the area so classified was even more extensive, but many of the more fertile lowland valleys and plains have been successfully cultivated and sown down to improved pastures.

For more than a century the pastoralists, and indirectly the country as a whole, have been utilising the natural resources of this tussock grassland, but true to Anglo-Saxon tradition, no long-term research was initiated to secure the information essential for a programme of improvement. We have been slow to appreciate the magnitude of the scientific problems involved, to realise the number of scientific disciplines directly concerned, and how closely they must work in unison if progress is to be made. (1)

Leonard Cockayne saw the problem in its true perspective, and in 1919 (2) stated " . . new methods, for improvement must be based on an accurate knowledge of the present plant covering of the area, of the natural changes taking place, of the climate and soil conditions to which the species are exposed, of the effects of the operations of man and his grazing animals, of the life histories and physiological requirements of the species, of the germinating capacity of

- their seeds, of the histories of the plant associations, and of other matters connected with the relation of the plants to their extremely complex surroundings."

I propose to take Cockayne's requirements as the basis for this paper and to outline as far as my information permits what effective action has been taken ; what, in my opinion, should have been done ; 
and; in the light of the advances in knowledge since Cockayne wrote his article; what should be our present policy.

\section{An Accurate Knowledge of the Present Plant Covering of the Area:}

We require a full inventory of the plant material present in the diverse habitats to be found within the tussock grasslands.

\section{(a) Systematics :}

For the systematic classification of the native flora the standard reference for field workers is Cheeseman's "Manual of New Zealand Flora," first published in 1906 and revised in 1925 . Since that time more complete collections of specimens, together with more detailed taxonomical, morphological, and cytological examinations of the plant material, have resulted in amendments and modifications within several important genera-for example, within the Danthonia group -and a new, comprehensive reference work is overdue. I understand that such a work is being assembled by officers of the Botany Division of the Department of Scientific and Industrial Research, and when it becomes available it will be possible to undertake ecological surveys of the tussock grasslands, as was done by Barker (3) in South Canterbury, and to produce maps of the present vegetative associations.

\section{(b) G enetics: -}

Together with the resolving of the systematic botany of the flora comes a stocktake of the genetic range to be found-within important species and knowledge of their methods of reproduction. The work of Connor (4) on Agropyron scabrum has thrown light on what can be expected from such studies, and I wish to emphasise that this systematic and ecological botany, together with the extension of these findings into the whole of the tussock grasslands, should be undertaken as a planned, co-ordinated part of a programme of improvement.

\section{An Accurate $K$ nowledge of the $\mathrm{N}$ atural Changes Taking Place and of the Climate and Soil Condi- tions :}

Here we are limiting the consideration' of the natural changes taking place to those occurring under the largely uncontrollable, inter-related elements of climate and soil. 


\section{(a) Climate :}

There are insufficient weather records available to permit detection of any change in climate by this means, but there is a growing volume of evidence to support the contention that there has been such a change, and that, on certain sites at least, this has been of sufficient magnitude to affect the plant covering $(5: 6)$. It is of fundamental importance that we have a measure of any changes in this factor, as it may well be that the effect of such alteration alone may render the indigenous flora unsuited to the new conditions. On the other hand, there may be a wide enough range of genetic variation to provide ecotypes which can survive such changes as may have taken place. It is difficult to isolate the influence of individual factors in the complex equation governing natural vegetative changes, but careful study of plant communities in the major habitats is required to answer the fundamental question as to whether improvement must rely on exotic plant material, or whether our native material warrants prior study. Mention will be made later to a technique being used to follow such natural changes.

\section{(b) Soil:}

The study of the soil conditions-its chemical and physical properties-and the mapping of the important soil types have progressed further than any other of Cockayne's requirements. The effect of the utilisation factor on soil profiles has been assessed, and this provides one reason, quite apart from any change in climate, why plant recovery appears negligible in certain sites even with complete spelling. Work has been begun on the microbiology of the tussock grassland soils, and studies are in progress on the identification and influence of the organisms in the rhizospheres of the important grass species.

\section{An Accurate Knowledge of the Effect of Man and of his Grazing Animals (including pests) :}

The plant cover of any area is composed of those plants which can best endure the existing conditions of soil, climate, and plant and animal competition, and the least static component of this equation is. man and his animals. There is no doubt that the modification known to have taken place in the tussock grasslands can be attributed in great measure to the arrival of the first settlers. 


\section{(a) Man:}

The direct effect of man was due to his use of fire to open up the ground cover and to remove unpalatable rank growth and encourage young, succulent regrowth. However, in accomplishing these objectives, the firestick has been used without regard for its effect on the plants themselves, and there is evidence to show that indiscriminate burning can destroy the micro-climate for the palatable plants, seriously weaken the tussocks themselves, and bare the soil to create conditions to encourage soil erosion (7). Today, over 100 years since the first deliberate burning of tussock, with continual arguments as to its pros and cons since that time, there is still no firm basis of factual information and measurement on 'which any decision on its future use can be made, and I suggest that this is a field, of the whole research programme which merits immediate attention.

\section{(b) Rabbit:}

Soon after his explosive spread throughout the tussock grasslands the rabbit was recognised as an important factor in the modification of the flora. It is certain that improvement to the cover, especially in the drier parts of these grasslands, can be attempted only when the rabbit problem is under control.

\section{(c) Sheep :}

Providing that his pests are controlled, the effect of man's grazing animals can be reduced to the effect of. sheep: what do they eat, when, and with what preferences. It seems incredible that after 100 years of sheep grazing in the tussock grasslands there is no agreement as to the answers to these questions. Cockayne stated that the first duty in an investigation into these lands was to ". . . ascertain with exactitude what species are eaten by sheep. ..." and in his own researches he conducted three palatability trials, two at Hanmer and one at Earnscleugh. However, in the light of subsequent plant and animal research the inferences drawn from his observations have had a profound and, I think, unfortunate effect on much of the work in tussock grasslands since 1920. My main criticism concerns the time of conducting these experiments. Cockayne was dealing with winter country, but two of the trials were undertaken in the summer and the other in September. I consider it most important that any palatability trial be conducted on typical tussock grassland, using typical run sheep at 
normal or only slightly above normal rates of stocking, and over the period when such country is usually stocked. These requirements have proved difficult to meet, particularly as hill sheep are nomadic, and the grazing extensive, thus complicating accurate observation and recording.

We have an 80-acre experimental hill block near Hawea Flat, and for the last two winters I have been searching for possible methods of determining sheep grazing habits. The area is typical of much winter country in Central O'tago, and half of it was oversown with promising grasses and clovers (nearly all of them introduced species) in 1949. There has been a variable response to this seeding. Previously bare, dark faces are now clothed with sown species, while the more exposed faces are showing recovery and spread of native species. Fine-wool hoggets have been used, the period of grazing has been from May until October, and the rate of stocking has been rather higher than usual44 hoggets in 1953 and 52 this year. For the first winter I spent a day on the area every three weeks and noted what I considered had been eaten. Actual observation of the sheep proved difficult and frequently a close examination of an area where an animal was known to have eaten failed to provide conclusive evidence. This last winter I placed $20 \mathrm{Ham}-$

blyn wire cages on different aspects, at different elevations, before grazing began, and at fortnightly intervals a comparison has been made between plants inside and outside these cages. These observations, together with further watching of the sheep themselves, have provided some useful information, but these methods are not sufficiently sensitive.

Observations so far indicate that the promising exotic species play little part in the diet of the sheep from the time of the first winter frosts, usually in late May or early June. Under the conditions prevailing the sheep have not eaten Poa colensoi, nor have they touched any Agropyron scabrum whose leaves are more than 2in long. Dichelachne crinita is eaten only occasionally. The wintering of the stock has been done by young plants of Agropyron scabrum, by several members of the Danthonia group, by Carex spp. and sorrel to a limited extent, and by the hair-grasses as soon as these come away early in the spring. It seems that for the critical period from June to September the species so strongly favoured by Cockayne's experiments are of little, if any, value, while most of 
the native grass species are able to provide nutritious feed for the stock. This may be a matter of different lignin placement within the plant leaves.

\section{An Accurate Knowledge of the Life Histories and Physiological Requirements of the Species :}

These are two important fields of study which have received little attention from research workers. Sewell (7) has made certain measurements on the growth and recovery after burning of plants of Festuca novae-xealandiae and Poa colensoi, but I know of no published data on the complete life history of any of our native tussock grasses or on their physiological requirements under the stress of utilisation.

\section{(a) Life Histories:}

The life histories of the individual species is a function of the reciprocal relationships between the individuals and their environment-their autecologyand to understand the ecology of a community, the ecologic life history of at least the most important plants in it must first be understood. Any studies so far undertaken to follow the behaviour of the plant associations under known conditions of soil., climate, and utilisation have been aimed at detecting gross population changes rather than the changes or development of any individual. Both Dick (8) and Sewell (9) have used point analyses for such work, and this method has been found difficult' to use in a constantly varying, several-storied tussock community, 'and its application appears to be limited to detecting differences in ground cover.

To obtain information on the ecology of our tussock grasslands and. indirectly on the life histories of its constituents! I have been trying out a method developed for similar studies in the rangelands of North America (10). Essentially I am recording the cover on a series of randomly chosen units of ground, and the success of this method depends on being able to return to exactly the 'same units of ground for. successive observations. Using a 50ft. steel tape and recording at $6 \mathrm{in}$. intervals with a $\frac{8}{4} \mathrm{in}$. loop on the end of a $12 \mathrm{in}$. shank, repeatability of the order of 90 to 96 per cent. was obtained on a difficult tussock species-browntop association near Alexandra, with similar results when dealing with a true bunch-grass community for which the method was designed. The next step was to establish the number of observations necessary on any 
site to include the range of speciespresent, and under a wide range of conditions in Central Otago it was found that 400 was the minimum. The $\frac{8}{4}$ in. loop has been found to be the most satisfactory size by the American workers, combining inter-observer accuracy and reading repeatability, and this size has been used in the studies so far made in this country. Last autumn a number of these transect clusters were put out in both Central Otago and in the Mackenzie Country.

This permanent line transect method is subject to certain limitations, even where repeatability of ring placement is nearly 100 per cent. It will provide a history of plant succession for a certain number of units of ground, but this does not mean that the same will apply to any or all other areas. To some extent this can be overcome by increasing the number of observations per site. Again, there can be such marked variations in environment within any one site that it may be difficult to detect any regular pattern of succession, or initial placement may give an atypical result for the important associations.

I hope that this technique, modified or adapted if necessary, will be of use in supplying information to help to 'meet several of Cockayne's requirements, particularly the effect of man and his grazing animals, but also the life histories of the important component species in various sites under various systems of management.

(b) Physiological Requirements under the Stress of Grazing :

We require to know in much more detail how the plant cover can resist the impact of the grazing animal and of burning, and quantitative data are required. I have begun a pilot experiment in Central Otago, using a near-pure association of Poa colensoi and subjecting it to a clipping technique used in the prairie of central Canada to establish growth patterns and reactions to utilisation of the native plants. Defoliation was begun last October and unfortunately only one replicate could be included. Each plot measured 20 links by 25 links, all were -reduced to a standard height above the crown of the plants in October, and a regular pattern of clipping was maintained at monthly intervals until April. The treatments were randomised within each series. Plot 1 in each was clipped on the 20th of each

month from November to April; plot 2 was first 
clipped on 20 December and monthly thereafter until April ; plot 3 was spelled for two months and then clipped every month; and so on, until plot 6, which was clipped only once, on 20 April. These treatments will be continued for several seasons,

Results from these first clippings have been surprising. A graph of the individual treatments in each of the two series shows close agreement, but a graph of the growth curve from the first series is very nearly the mirror image of the similar curve from the clip-ping of the second series.

A further two replicates are being included in this trial this year.

As the sheep grazing studies are pushed ahead the important grasses from a production point of view will be identified and it is intended to subject these to a similar pattern of simulated grazing. These studies should give some idea of the extreme of utilisation which the plant can tolerate, and also, and more important, they should enable us to propose a plan of utilisation to secure optimum sustained production.

\section{An Accurate Knowledge of the $\mathrm{H}$ istories of the} Plant A ssociations :

This knowledge of the plant associations in the different environments and under the different types and intensities of utilisation to be found in the tussock grasslands is the summation of Cockayne's individual requirements.

\section{An Accurate $K$ nowledge of the Germinating capac- ity of their Seeds:}

Laboratory tests have been made for most of the species present in the tussock grasslands, and it seems that, for the perennial species, with a few exceptions, the germinating capacity of their seed is low. In the field, under the unpredictable but mainly exposed dry conditions, establishment capacity from seed. seems to be very poor in most cases.

The immensity and complexity of our problem becomes evident when we survey it from the vantage point of 1954. It is obvious that the end of the century will still find much of Cockayne's programme unfinished. Some progress has been. made-more in some directions than in others-but $m y$ criticism is that such work as has been undertaken has been done in isolation. If ever a problem 'called for combined operations, this one does. I realise that the field is too im- 
mense to bring all the sciences concerned into one place, but I would suggest that progress can be made only by gathering a group of workers representing the field approach into one' place and there to launch a well-knit, long-term attack on Cockayne's operational orders.

Conferences such as this are valuable and essential, and. there are scientific journals which can act as media for the exchange of information among research workers, but neither of these can hope to replace the sort of assault I am suggesting. The Tussock Grassland Research Committee, comprising representatives of Government agencies dealing with tussock grassland, is engaged on assembling information on what has been done in these lands, but it has so far been unwilling or unable to replace the present spectacle of individual workers employed by separate Departments, by Universities, and by local bodies working in. scattered localities, with any measure of co-ordination largely accidental, by a positive, organised programme of investigation.

Although I have discussed Cockayne's requirements individually, it must be realised that there is a close inter-relationship between them and that they are merely artificial divisions of the broad field of the ecology of the tussock grasslands.

For the first time since their introduction the rabbits are now being brought under control and improvement is possible in many previously infested areas. The runholders are able to undertake a programme of improvement and there is an urgent need for increased production from every available acre in New Zealand. Nearly 30 per cent. of the occupied land of this country is classed as tussock grassland in which no major improvement has been attempted, but progress can be assured only by tackling the problem logically, effectively, and quickly.

\section{REFERENCES}

1. Buchanan, J. (1875) : Trans. N.Z. Inst. 1, 181 2nd Edition).

2 . Cockayne, L. (1919) : N.Z.J. Ag. 28, 1.

3. Barker, P. (1953): N.Z.D.S.I.R. Bull. 107.

4. Connor, H. (1954) : N.Z.J. Sci. Tech. 35, 315.

5. Raeside, J. D. (1949) : Trans. Roy. Soc. N.Z. $77,153$. 
6. Holloway, J. T. (1948) : N.Z.J. Forestry 5,401.

7. Sewell, T. G. (1952) : N.Z. Grass. Assoc. 14, 123.

8. Dick, R. (1952) : N.Z. Grass.! Assoc. 14, 114.

9. Sewell, T.G.-Unpublished work in Waimakariri Basin.

10. Parker, K. (1951) : U.S. Forest Service Pubn. $26 \mathrm{pp}$.

\section{DISCUSSION}

Q. Are there not management practices that will give protection and production?,

A. As we find in much more detail what grasses are playing a part in wintering sheep then we can make recommendations. We are dealing with very dry country. In the department nursery area at Pisa Flats 350 species have been tested of which about five were found to be adapted to the environment, and when we put them out they did not play the part we had hoped.

Q. Would oversowing and manuring of native pastures affect palatability?

A. In the Mackenzie Country oversowing and topdressing have been done and we are trying to get information there.

Q. When the speaker was in North America did he find any grass on similar country worth trying here ?

A. Generally climatic conditions there are so dissimilar that we would not expect similar performances from their grasses. From Oregon on the West Coast we have some material we are trying, but it does not seem to do the same with us as with them.

Q. In North Canterbury nassella tussock that is invading all the dry north-west faces is being cleared with T.C.A. Is there anything we can put back there ?

A. (Leitch): There was a cover there. before nassella, so we know it will take a cover. How long after the removal of the nassella it will be before it is replaced we do not know. 